\title{
ALFABETIZAÇÃO CIENTÍFICA E TECNOLÓGICA - ACT NA FORMAÇÃO ACADÊMICA SUPERIOR
}

\author{
Scientific and Technological Literacy - ACT in higher academic education
}

\author{
Edgar Henrique Hein Trapp - FIESC/UNIESP/Brasil \\ Andreia Aparecida Guimarães Strohschoen- UNIVATES/Brasil \\ Eniz Conceição Oliveira- UNIVATES/Brasil \\ José Claudio Del Pino- UNIVATES/Brasil
}

RESUMO: Este artigo aborda um estudo sobre a Alfabetização Científica Tecnológica - ACT e a relação com a Alfabetização Científica - AC e o Letramento Científico - LC. Além da situação da formação acadêmica cidadã, esta, encontrando-se na contramão pelo fato do aluno que ingressa no nível superior, apresentar grandes dificuldades no entendimento e no letramento científico em relação a escrita, leitura e interpretação de textos científicos. Obtivase contextualizar a dificuldade da alfabetização/letramento científico do aprendente ao ingressar no nível superior. A pesquisa foi produzida por uma revisão de literatura, livros e bibliotecas virtuais: Google Acadêmico; Scielo; PUC Artigos entre outros. As fontes utilizadas compreendem o período de 2001 a dezembro de 2017. Como critério de inclusão, foram escolhidos 17 escritos literários, artigos e dissertações relacionados ao tema da pesquisa. Constata-se que, a dificuldade da alfabetização e do letramento cientifico manifestado pelos aprendentes universitários está relacionado a decodificação dos textos científicos, pois estes, ao ingressarem no nível superior, sabem ler e escrever de maneira social, porém, esternalizam dificuldades em compreender a cientificidade dos textos apresentados, pontuados como enculturados científicos. $\mathrm{O}$ artigo menciona o quanto necessitamos (re)construir o letramento e a alfabetização científica ao recebermos os aprendentes que iniciam a sua vida academia superior, compreendendo dentro das discussões literárias realizadas, que o aluno sabe ler e escrever, todavia, não sabe decifrar a leitura e escrita em um meio da ACT. Vislumbramos como possível resultado é uma intervenção direta do ensinando, dentro do processo da experenciação, o gosto pela escrita e leitura acadêmica.

Palavras chaves: Alfabetização Científica. Enculturação. Ensino Superior. Formação Cidadã.

\begin{abstract}
This article deals with a study on Scientific and Technological Literacy - ACT and the relationship with Scientific Literacy - AC and Scientific Literacy - LC. In addition to the situation of the academic formation of the citizen, this one, being in contrast to the fact that the student who enters the higher level, presents great difficulties in the understanding and the scientific literacy in relation to writing, reading and interpretation of scientific texts. It is possible to contextualize the difficulty of the literacy / scientific literacy of the learner when entering the higher level. The research was produced by a review of literature, books and virtual libraries: Google Scholar; Scielo; PUC Articles among others. The sources used include the period from 2001 to December 2017. As an inclusion criterion, 17 papers, articles and dissertations related to the research theme were chosen. It is noted that the difficulty of literacy
\end{abstract}

Educação, Psicologia e Interfaces, Volume 3, Número 2, p. 136-147, Maio/Agosto, 2019. 
and scientific literacy manifested by university learners is related to the decoding of scientific texts, since when they enter the higher level they are able to read and write in a social way, but they slander difficulties in understanding scientificity of the texts presented, punctuated as enculturated scientists. The article mentions how much we need to (re) construct literacy and scientific literacy when we receive learners who begin their life superior academy, understanding within the literary discussions carried out, that the student can read and write, however, does not know how to decipher reading and written in an ACT medium. We glimpse as possible result is a direct intervention of the teacher, within the process of the experimentation, the taste for writing and academic reading.

Keywords: Citizen Training. Enculturation. Higher education. Scientific Literacy.

\section{INTRODUÇÃ̃O}

Para tentar compreender a situação da Alfabetização Científica Tecnológica - ACT, quando abarcamos esta, na formação acadêmica superior, primeiro é necessário um recorte da história no qual, por exemplo, Pella et al. (1966 apud SASSERON; CARVALHO, 2011, p. 62) já elucidavam uma definição para o conceito de AC (alfabetização científica) e, examinando trabalhos divulgados à época, concluíram que “[...] para uma pessoa ser considerada alfabetizada cientificamente deve ter conhecimento das relações entre Ciência e Sociedade." Ainda acrescentaram: “[...] conhecer a natureza da ciência; diferenciar Ciência de Tecnologia; possuir conhecimento sobre conceitos básicos das ciências; e, por fim, perceber e entender as relações entre as ciências e as humanidades". (PELLA et al. 1966 apud SASSERON; CARVALHO, 2011, p. 62).

Em uma passagem literária de Lourenço (2017, p. 223), este relata que existe também uma preocupação em relação aos estudos sobre letramento acadêmico. Para este autor, tais situações:

[...] evidenciam que diversos fatores externos interferem na forma como os estudantes estabelecem contato com os gêneros acadêmicos, opondo-se à perspectiva do discurso do déficit. Letramentos acadêmicos não são apenas um conjunto de habilidades de escrita, envolvem práticas diversas de letramentos na universidade, questões de identidade e poder na e da instituição.

Sasseron e Carvalho (2011, p. 64) citam que Gerard Fourez ${ }^{1}$ que, também angustiado com a formação escolar dos cidadãos, mencionou em seu livro "Alphabétisation Scientifique et Technique - Essai sur les finalités de l'enseignement des sciences"2 (1994), que há preciosos contextos sobre a importância da Alfabetização Científica e Tecnológica e, fez uma

Educação, Psicologia e Interfaces, Volume 3, Número 2, 136-147, Maio/Agosto, 2019. 
Edgar Henrique Hein Trapp, Andreia Aparecida Guimarães Strohschoen, Eniz Conceição Oliveira e José Claudio Del Pino

comparação à seriedade desta alfabetização, principalmente, para a sociedade atual assim como esta teve importância ao processo de alfabetização no final do século XIX, para a sociedade daquela época. E Fiad (2011) inclui às discussões anteriores que na universidade, os aprendentes são provocados a produzirem diferentes estruturas da escrita acadêmica, todavia, na gênesis de suas produções textuais, eles perceberam que o conhecimento alcançado na ensinagem básica não era satisfatório porque há uso específico da escrita no contexto universitário, uso que contemporizam de outros contextos. Soares (2005 apud AMARAL, 2014, p. 41) nesta ótica sobre a AC, faz um alerta que:

[...] alfabetização científica não pode ser encarada como uma forma tecnicista, um mero instrumento de desenvolvimento social, mas, sim, deve caracterizar-se como um processo significativo de produção de atores sociais em sujeito crítico, capazes de fazer uma leitura de mundo e intervir em diferentes contextos socioculturais, pela aplicação responsável de conhecimentos construídos ao longo de sua formação.

Diante do exposto, o presente artigo tem como objetivo o de contextualizar a dificuldade da alfabetização e do letramento científico do aprendente ao ingressar no nível superior.

E, na continuidade, temos a revisão sistemática da literatura como metodologia de pesquisa qualitativa, com aportes de teóricos que visam esta discussão da Alfabetização Científica e Tecnológica Alfabetização Científica e o Letramento Científico dos aprendentes ao ingressarem no nível universitário e a dificuldade apresentada por estes na interpretação de textos científicos, quando há uma exigência social que tais alunos tenham uma formação cidadã.

\section{A ALFABETIZAÇÃo CinetífiCA TECNOLÓGICA - ACT COMO FORMAÇÃo CIDADÃ}

Ao iniciar as discussões literárias sobre a ACT e sua relação com a AC e LC, talvez seja necessário buscar uma resposta à um primeiro indagamento: Há domínio de conhecimentos científicos e tecnológicos necessários para formação cidadã? Chassot (2003 apud SANTOS, 2007) já trazia que o cidadão deveria ter tal conhecimento para desenvolver-se em seu cotidiano. Ainda Chassot (1994 apud AULER; DELIZOICOV, 2001, p. 124) sintetizam o conhecimento científico por dois 'axiomas', sendo os quais “[...] a superioridade teórica e prática da ciência para qualquer situação. A nível teórico, seria um conhecimento superior a todos os demais. No campo prático, seria a melhor forma de conhecimento para resolver problemas situados desde o campo técnico até o ético".

Educação, Psicologia e Interfaces, Volume 3, Número 2, p. 136-147, Maio/Agosto, 2019.

ISSN: 2594-5343. DOI: 
Nessa perspectiva, é importante ressaltar ao que Brasil (1988 apud DIESEL et. al. 2016, p.59) trouxe em relação a formação cidadã. Para o autor "A Constituição Federal já previu que a educação fosse direcionada para o preparo da cidadania". Fato que Motta-Roth (2007) corroborou sobre a questão do desenvolvimento em que este letramento científico tem o papel decisivo na formulação de uma sociedade mais organizada para conjeturar sobre seus próprios problemas e estabelecer as necessárias soluções. Moura (2000 apud AMARAL, 2014, p. 12) segue por esta mesma linha de pensamento e, em seu discurso sobre o fato do conhecimento científico, ela traz que:

[...] evidencia-se o papel do conhecimento científico como ferramenta social na melhoria da qualidade de vida. Desta forma, o avanço científico e tecnológico traz consigo a necessidade de educar cientificamente sujeitos para que possam aplicar seus conhecimentos no cotidiano.

Terzi e Scavassa (2005) adicionam que o letramento científico de um grupo tem atributos de determinado tempo e espaço, que sofre influencia por categorias sociais, econômicas e culturais como já mencionado por autores como Motta-Roth (2007), Sasseron e Carvalho (2011) e Diesel et al. (2016). Nesta situação, Oliveira (2009) acresce que o letramento possui duas dimensões. Primeiro, que o letramento possui uma dimensão social, sendo esta, relacionada aos fatores e às combinações sociais que tem o regulamento sobre o uso da escrita dentro de uma comunidade ou de uma forma da atividade humana e, uma segunda dimensão individual, dirigida à causa das experiências de vida de cada indivíduo, sendo este, inserido em uma comunidade.

Sobre esta situação, Lourenço (2017) comenta sobre as duas dimensões citadas por Oliveira (2009), as quais demonstram ao contrário do que foi apontado no discurso de crise e de déficit, ao mencionar que os estudantes que entram no ensino superior não sabem ler e escrever, porém, são sujeitos letrados e com experiências de leitura e escrita instaladas na escola e em outros campos como a família, a igreja, o clube entre outras. Tais aprendentes apenas não detêm os letramentos que circulam no espaço acadêmico/universitário.

Souza (2012, p. 156) em uma pesquisa da Fundação Nacional de Desenvolvimento de Ensino Superior Particular (Funadesp), focaliza uma possível resposta ao questionamento proposto anteriormente, em que, para este autor, a situação das dificuldades do letramento científico nos acadêmicos encontra-se na contramão pelo motivo de:

Educação, Psicologia e Interfaces, Volume 3, Número 2, 136-147, Maio/Agosto, 2019.

ISSN: 2594-5343. DOI: 
[...] nossos alunos no trabalho com textos - tanto de interpretação quanto de produção textual - advêm de problemas relacionados à falta de práticas de leitura e escrita e ao desconhecimento de estratégias que poderiam ajudá-los nessas tarefas, já que tais atividades muitas vezes ficam em segundo plano nas escolas de nível fundamental e médio e pouco são incentivadas em casa.

Seguindo o caminho da possível resposta, para Oliveira (2009) há uma visão dos professores sobre o déficit dos aprendentes, porém, na realidade, tais fracassam nas atividades iniciais apresentadas pela universidade pela razão de não terem sido sujeitados anteriormente aos procedimentos linguísticos e sociais exclusivos do domínio universitário e, não por não terem o domínio sobre a leitura e escrita.

Neste viés, Cruz (2007, p. 7) salienta ainda que "[...] as práticas de letramento nas disciplinas acadêmicas estão associadas ao uso e às funções da escrita em comunidades e contextos específicos”. Ela ainda busca explicações para esta questão do letramento e seus desafios em vertentes teóricas que concebem a leitura, a escrita e o próprio letramento como exercícios sociais citados em Barton (1994); Gee (2000) e Street (1994,1995), pois os argumentos referem preciosos subsídios para o campo dos letramentos na esfera acadêmica, ao adentrarem em uma nova abordagem para a concepção da escrita em ensinamentos de nível superior, como probabilidade de desafio para preencher as diferenças culturais e, realça que “[...] essa visão, modalizando, portanto, a noção de 'deficit' cognitivo observado nas produções textuais dos alunos" (CRUZ, 2007, p. 6-7).

A mesma autora acrescenta que a escrita na academia é compreendida em nível de epistemologia, devendo, então “[...] o letramento nesses contextos ser conceituado a partir de três perspectivas que se sobrepõem: (1) um modelo de estudo de habilidades, (2) um modelo de socialização acadêmica e (3) um modelo de letramentos acadêmicos" (CRUZ, 2007, p. 67).

Ainda sobre a questão do processo epistemológico do conhecimento científico, Bachelard (1996), propôs o ato de conhecer como um ato de negação. Para ele, o método de construção das ciências ocorre por meio de impedimentos, e o desenvolvimento da cientificidade se dá com a superação dos entraves.

A despeito da complexidade do tema até aqui exposto, ainda há estudos de Motta-Roth (2007, p. 13), sendo que a autora busca trazer de forma mais prática a questão sobre o termo dual da CT (Ciência e Tecnologia), pontuando que “[...] torna-se importante examinar o modo como os discursos acerca da ciência e da tecnologia se dinamizam, se espalham, se atravessam em nossa vivência e na conformação de nossos modos de ser e pensar".

Educação, Psicologia e Interfaces, Volume 3, Número 2, p. 136-147, Maio/Agosto, 2019. ISSN: 2594-5343. DOI: 
Sobre o fato de nossa vivência e, de que forma agimos e pensamos, Sasseron e Carvalho (2008) trazem à luz da compreensão e do entendimento das relações existentes entre o quadrilátero da ciência, tecnologia, sociedade e meio-ambiente e, transcorre pelo reconhecimento de que aproximadamente todo evento da vida de alguma pessoa tem sido influenciado, de um certo ponto, pelas ciências e tecnologias. Neste sentido ao que foi apresentado até o momento, há a necessidade de ser trabalhado quando temos na ideia o desejo de um futuro benéfico e sustentável para a sociedade como um todo.

Há também uma preocupação, a priori, sobre a definição da AC - Alfabetização Científica ou LT - Letramento Científico relacionada a este conhecimento científico definido por Laugksch (apud SANTOS, 2007, p. 476) como:

[...] o entendimento do significado de AC/LC tem sido objeto de preocupação de educadores em ciência, cientistas sociais, pesquisadores de opinião pública, sociólogos da ciência, e profissionais envolvidos na educação formal e nãoformal em ciências, como professores [...].

A propósito desta questão do conhecimento científico, vale ressaltar os comentários de Diesel et. al. (2016) em relação ao próprio conhecimento do ensinante. Para estes autores os maiores provocadores do conhecimento ainda são estes profissionais. Todavia, eles contribuem à uma situação já discutida por Bourdieau (2011), que ele chamou de violência simbólica da escola e o papel subjugado do professor. Numa passagem literária, eles trazem uma reflexão sobre este fato, em que:

São eles que devem trazer práticas pedagógicas inovadoras e proporcionar aulas com esse enfoque aos alunos. Acredita-se que os professores percebam essa importância, entretanto esbarram num cotidiano com muita carga horária de trabalho, falta de tempo para preparo de aulas, deficiência na formação inicial e continuada, falta de apoio pedagógico, e, por que não dizer, falta de entusiasmo e motivação em algumas situações. (DIESEL et al. 2016, p. 60).

E, ainda comentando sobre a violência simbólica, como um processo em cadeia, muitas vezes o ensinante acaba reprimindo o aprendente em sala de aula no procedimento da curiosidade científica e do questionamento. Situação que Freire e Fundez (1985 apud DIESEL et al. 2016, p. 63-64) comentam sobre este fato, em que a:

[...] curiosidade do estudante às vezes pode abalar a certeza do professor. Por isso é que, ao limitar a curiosidade do aluno, a sua expressividade, o professor autoritário limita a sua também. Muitas vezes, por outro lado, a pergunta que

Educação, Psicologia e Interfaces, Volume 3, Número 2, 136-147, Maio/Agosto, 2019.

ISSN: 2594-5343. DOI: 
Edgar Henrique Hein Trapp, Andreia Aparecida Guimarães Strohschoen, Eniz Conceição Oliveira e José Claudio Del Pino

o aluno, livre para fazê-la, faz sobre um tema, pode colocar ao professor um diferente, do qual lhe será possível aprofundar mais tarde uma reflexão mais crítica.

Mesmo que Sasseron e Carvalho (2008) citam em parte, as discussões de JiménezAleixandre, Bugallo Rodríguez e Duschl (2000) sobre a capacidade dos ensinantes aumentarem o número de questionamentos em sala de aula e ainda não terem domínio total sobre alguns conteúdos. As mesmas autoras complementam: "As habilidades a que nos referimos também devem cooperar em nossas observações e análise de episódios em sala de aula para elucidar o modo como um aluno reage e age quando se depara com algum problema durante as discussões". (SASSERON; CARVALHO, 2008, p. 337).

Para Almeida (2007, p.22) “[...] um indivíduo letrado consegue ter atitudes para vivenciar situações-problema e resolvê-las, ao mesmo tempo em que certas vivências contribuirão para que se consolidem suas habilidades de leitura e escrita”. É relevante conduzir o aluno para compreender, a priori, a função do texto no exercício social, pois isso conduz a entender os pontos formais do texto, ou seja, a compreensão do tipo de texto que ele poderá produzir e em qual gênero precisará escrever para alcançar a função social aspirada (TERZI; SCAVASSA, 2005).

Outro ponto importante a ressaltar neste momento, cabe uma pergunta formulada por Mamede e Zimmermann (2005, p. 2) sendo esta: "Como promover o letramento científico dos alunos, dentro de uma perspectiva CTS, se os professores, em sua maioria, não são eles próprios letrados cientificamente?"

Houve então uma manifestação por parte de Norris e Phillips (2003 apud SANTOS, 2007, p. 478) que, no afã de discutir a educação científica e uma possível resposta ao questionamento anterior, apresentaram dois pontos importantes que procuram compreender a questão da educação científica, os quais temos como a "[...] habilidade de usar conhecimento científico na solução de problemas e, conhecimento necessário para participação inteligente em questões sociais relativas à ciência $[\ldots]$ ”.

Com base nos argumentos pontuado pelos autores até o momento e na perspectiva de responder aos questionamentos propostos anteriormente, busca-se então, ancoragem nas palavras de Driver et al. (1994 apud SANTOS, 2007, p. 481), em que “[...] consideram a educação científica um processo de enculturação em que o aluno aprende a linguagem, o modo de pensar, de expressar-se e de justificar os seus argumentos". Ainda a "enculturação científica" é utilizada pelos autores Carvalho e Tinoco (2006), Mortimer e Machado (1996

Educação, Psicologia e Interfaces, Volume 3, Número 2, p. 136-147, Maio/Agosto, 2019. 
apud SASSERON; CARVALHO, 2011, p. 60) no sentido de “[...] designarem o objetivo desse ensino de Ciências que almeja a formação cidadã dos estudantes para o domínio e uso dos conhecimentos científicos e seus desdobramentos nas mais diferentes esferas de sua vida".

Por este ângulo, Grinspun (1999) confirmou que a educação tecnológica deve "[...] ser também vivenciada em todos os segmentos de ensino, visando à formação de cidadãos críticos que possam transformar o modelo de desenvolvimento tecnológico de nossa sociedade atual (GRINSPUN 1999 apud SANTOS, 2007, p. 483). Pode-se observar que Diesel et al. (2016, p. 60) seguem ao encontro dos anseios de tecer uma explicação sobre a questão do letramento científico e tecnológico, ancorados em valores éticos e princípios democráticos e a formação do cidadão. Dessa forma,

[...] a escola promoverá o Letramento Científico e Tecnológico (LCT), ou seja, a formação de cidadãos que não só serão capazes de compreender os problemas políticos, ambientais, sociais, econômicos enfrentados pelo mundo, como também estarão preparados para enfrenta-los, pois terão uma visão crítica e comprometida com a sociedade (DIESEL et al. 2016, p. 60).

Outro ponto, sobre o qual encontramos amparo, está na reflexão de Lemke (1990), no que diz respeito ao modo como uma pessoa letrada cientificamente é apropriada ao ato de comunicar-se cientificamente e, atuar como pertencente a comunidade científica. Importa salientar aqui o que foi comentado por Bevilaqua (2011, s/p.) em que:

[...] há uma necessidade de formulação de subsídios para o letramento científico, sócio-culturalmente situado, por meio do qual se busca construir uma prática de ensino que não apenas considere os conhecimentos prévios dos sujeitos aprendentes, suas práticas sociais, a sua historicidade, mas que avalie seus propósitos junto à comunidade a que serve, definindo-se a partir de um caráter intervencionista e responsivo àquela vida social, e que entende ciência enquanto concepção indissociável do desenvolvimento humano e social.

Todavia, temos de nos ater também ao que foi manifestado por Auler e Delizoicov (2001) em que este desenvolvimento científico-tecnológico não deve ser analisado como um procedimento neutro e, que deixa ilesas as composições sociais sobre as quais atua. Para eles, tanto a Ciência como a Tecnologia não devem ser consideradas como únicas alavancas para a mudança que afetam sempre, ou seja, não devem ser as únicas responsáveis pela transformação do conhecimento. Neste sentido, "esperar por uma solução apenas técnica, que não inclua medidas sociais e culturais, é mover-se em um terreno ilusório" (AULER; DELIZOICOV, 2001, p. 125).

Educação, Psicologia e Interfaces, Volume 3, Número 2, 136-147, Maio/Agosto, 2019.

ISSN: 2594-5343. DOI: 
Gómez (1997 apud AULER; DELIZOICOV, 2001, p. 125) remete também a seguinte situação sobre este determinismo tecnológico. Para o autor, em primeiro lugar há a questão de que a “[...] mudança tecnológica é a causa da mudança social, considerando-se que a tecnologia define os limites do que uma sociedade pode fazer" e, uma segunda situação pontuada pelo mesmo autor, remete-nos ao outro ponto em que "[...] a tecnologia é autônoma e independente das influências sociais".

E, finalizando esta construção reflexiva teórica sobre o fato de pensar em uma mudança social e a ACT dentro da esfera universitária, necessitamos observar o processo do letramento cientifico e a relação biopsicossocial do homem. Para Santos e Schnetzler (1977 apud DIESEL et al. 2016, p. 60) esta relação está no fato de que "Os estudantes tendem a integrar sua compreensão pessoal do mundo natural (conteúdo da ciência) com o mundo construído pelo homem (tecnologia) e o seu mundo social do dia a dia (sociedade)".

\section{CONSIDERAÇÕES FINAIS}

Em análise aos textos dos teóricos mencionados, verificou-se que a dificuldade da alfabetização e do letramento cientifico, em relação aos aprendentes universitários, está pautada diretamente na decodificação dos textos, pois estes, ao ingressarem na esfera acadêmica, já possuem um conhecimento sobre a leitura e a escrita, contudo, de maneira social. Assim, a maior dificuldade destes, encontra-se atrelada ao fato de não compreenderem e decodificarem as discussões relativas a cientificidade dos textos apresentados pelos ensinantes dentro do espaço de formação cidadã.

É percebível que a proposta de um letramento científico direcionado ao aprendente de nível superior, revela estudos bem sucedidos na Inglaterra e nos Estados Unidos, por exemplo, e, também como outros países que estão no caminho em diversas partes do mundo, com esse mesmo perfil teórico e epistemológico, já discutido por autores apresentados neste artigo.

Há também a necessidade de se vislumbrar que o ensino superior não pode ser visto por uma linha homogênea e universal, pois há particularidades de cada aprendente em sua cultura individual, linguística e histórica social.

Sendo assim, necessitamos uma (re)construção do letramento e alfabetização científica quando recebemos os aprendentes ingressantes na academia superior, pois foi percebível, nas discussões literárias apresentadas que o aluno sabe ler e escrever, contudo, não sabe entender a leitura e escrita em um meio da ACT, sendo necessário assim, a intervenção direta do

Educação, Psicologia e Interfaces, Volume 3, Número 2, p. 136-147, Maio/Agosto, 2019. 
ensinante, promovendo a curiosidade, a experenciação e o gosto pela escrita e leitura acadêmica.

\section{Notas de rodapé}

${ }^{1}$ Gérard Fourez é um filósofo francês, nascido em maio de 1937. O autor é licenciado em filosofia, matemática, doutor em Física Teórica e professor da Universidade de Namur, onde até pouco tempo ensinou epistemologia, ética e filosofia da educação, onde também fundou o Departamento de Filosophie de L'Homme de Science. É também professor visitante da Universidade da Filadélfia (A Inspiração).

${ }^{2}$ Alfabetização científica e técnica: Ensaios sobre a finalidade de educação em ciência (tradução do autor).

\section{REFERÊNCIAS BIBLIOGRÁFICAS}

FOUREZ, Gérard. A inspiração. Disponível em:

<http://ilhasderacionalidade.com.br/inspiracao.php>. Acesso em 04 set. 2018.

ALMEIDA, Maria Leoneide Rodrigues de. Letramento no ensino superior: perfil dos alunos no primeiro ano de cursos de duas IES privadas do DF a partir de suas próprias percepções. 113 f. Dissertação de Mestrado em Educação, Universidade Católica de Brasília, Brasília, 2007. Disponível em:

<file:///C:/Users/Hedgar\%20Trapp/Documents/MESTRADO\%20UNIVATES/ALFABETIZ A\%C3\%87\%C3\%830\%20CIENT\%C3\%8DFICA/Textos\%20completo.pdf $>$. Acesso em 18 ago. 2018.

AMARAL, Lisandra Catalan do. Letramento científico em ciências: investigando processos de mediação para a construção dos saberes científicos em espaços não formais de ensino. 114 f, Tese de Doutorado, Programa de Pós-Graduação em Educação Porto Alegre, 2014.

Disponível em: 〈http://tede2.pucrs.br/tede2/bitstream/tede/3814/1/459175.pdf > . Acesso em 23 ago. 2018.

AULER, Décio; DELIZOICOV, Demétrio. Alfabetização científico-tecnológico para quê?

Rev. Ensaio, Belo Horizonte, v.03, n.02, 2001. Disponível em:

$<$ http://www.scielo.br/pdf/epec/v3n2/1983-2117-epec-3-02-00122.pdf $>$. Acesso em 11 ago. 2018.

BACHELARD, Gaston. A formação do espírito científico: contribuição para uma psicanálise do conhecimento. Rio de Janeiro: Contraponto, 1996.

BEVILAQUA, Raquel. Ciência e letramento no ensino básico - uma relação possível? $1^{\text {a }}$ Jornada de multiletramento. Na formação acadêmica, docente e profissional. 2011. Disponível em: < http://w3.ufsm.br/lablerx/images/betynaletras/resumos_sessao_ii.pdf > Acesso em 11 ago. 2018.

BOURDIEU, P. O poder simbólico. 15. ed. Rio de Janeiro: Bertrand Brasil, 2011.

Educação, Psicologia e Interfaces, Volume 3, Número 2, 136-147, Maio/Agosto, 2019.

ISSN: 2594-5343. DOI: 
CRUZ, Maria Emilia Almeida da. O letramento acadêmico como prática social: Novas abordagens. Gestão e Conhecimento, v. 4, n. 1, art. 1, julho/ novembro, 2011. Disponível em: 〈https://www.pucpcaldas.br/graduacao/administracao/revista/artigos/v4n1/v4n1a1.pdf $>$. Acesso em 18 ago. 2018.

DIESEL, Aline et al. Contribuições da língua portuguesa para uma proposta de letramento científico e tecnológico no contexto escolar. Revista Eletrônica Debates em Educação Científica e Tecnológica, v. 6, n. 2, 2016. Disponível em: https://ojs.ifes.edu.br/index.php/dect/article/view/159 . Acesso em 16 ago. 2018. Doi: https://doi.org/10.36524/dect.v6i02.159

FIAD, Raquel Salek. A escrita na universidade. Revista da ABRALIN, v. Eletrônico, n. Especial, p. 357-369, $2^{a}$ parte, 2011. Disponível em: https://revistas.ufpr.br/abralin/article/view/32436 Acesso em 16 ago. 2018. Doi: http://dx.doi.org/10.5380/rabl.v10i4.32436

LEMKE, Jay. L. Talking science: Language, learning and values. Norwood, NJ: Ablex, 1990.

LOURENÇO, Daiane da Silva. Conflitos entre as expectativas de professores e de estudantes universitários em práticas de letramento acadêmico. Travessias Interativas - Artigos. Vol. 14, n. 2, 2017. Disponível em: < https://seer.ufs.br/index.php/Travessias/article/view/9133/7156>. Acesso em 19 ago. 2018.

MAMEDE, Maíra; ZIMMERMANN, Erika. Letramento científico e CTS na formação de professores para o ensino de ciências. Enseñanza de las ciencias, número extra. VII congresso, 2005. Disponível em:

<https://ddd.uab.cat/pub/edlc/edlc_a2005nEXTRA/edlc_a2005nEXTRAp320letcie.pdf $>$. Acesso em 16 ago.2018.

MOTTA-ROTH, Désirée. Letramento científico: sentidos e valores. LABLER - Laboratório de Pesquisa e Ensino de Leitura e Redação Programa de Pós-Graduação em Letras Universidade Federal de Santa Maria. Trabalho desenvolvido dentro do projeto Análise crítica de gêneros com foco em artigos de popularização da ciência (MOTTA-ROTH, 2007), com bolsa PQ/CNPq n 301962/2007-3. Disponível em: <file:///C:/Users/Hedgar\%20Trapp/Downloads/3983-17665-1-PB.pdf>. Acesso em 16 ago. 2018.

OLIVEIRA, Eliane Feitoza. Letramento Acadêmico: principais abordagens sobre a escrita dos alunos no ensino superior. In: Encontro Memorial do ICHS, 2. Mariana. Anais Mariana: ICHS, 2009.

SANTOS, Wildson Luiz Pereira dos. Educação científica na perspectiva de letramento como prática social: funções, princípios e desafios. Revista Brasileira de Educação, v. 12 n. 36 set./dez, 2007. Disponível em: 〈http://www.scielo.br/pdf/rbedu/v12n36/a07v1236.pdf>. Acesso em 11 ago.2018.

SASSERON, Lúcia Helena; CARVALHO, Anna Maria Pessoa de. Almejando a alfabetização científica no ensino fundamental: A proposição e a procura de indicadores do

Educação, Psicologia e Interfaces, Volume 3, Número 2, p. 136-147, Maio/Agosto, 2019. ISSN: 2594-5343. DOI: 
processo. Investigações em Ensino de Ciências, v.13, n.3, 2008. Disponível em: <file:///C:/Users/Hedgar\%20Trapp/Downloads/445-889-1-SM\%20(1).pdf>. Acesso em 16 ago. 2018.

SASSERON, Lúcia Helena; CARVALHO, Anna Maria Pessoa de. Alfabetização científica: uma revisão bibliográfica. Investigações em Ensino de Ciências, v.16, n.1, 2011. Disponível em: < file:///C:/Users/Hedgar\%20Trapp/Downloads/246-482-1-SM.pdf>. Acesso em 16 ago. 2018.

SOUZA, Clinio Jorge de. Letramento acadêmico - da escrita à leitura científica. Anuário da produção acadêmica docente. Instituto de Pesquisas Aplicadas e Desenvolvimento Educacional - IPADE, v.6, n.15, 2012. Disponível em: <http://repositorio.pgsskroton.com.br/bitstream/123456789/1494/1/Artigo\%2011.pdf>. Acesso em 11 ago. 2018.

TERZI, Sylvia Bueno; SCAVASSA, Júlia Sant'Ana. Mudanças na concepção de escrita de jovens e adultos em processo de letramento. Revista Brasileira de Linguística Aplicada, Campinas, v. 5, n. 1, p. 181-207, 2005.

\section{Credenciais da/os autora/es}

TRAPP, Edgar Henrique Hein. Aluno do Mestrado Acadêmico em Ensino pela Universidade do Vale do Taquari-UNIVATES (2018). O presente trabalho foi realizado com apoio da Coordenação de Aperfeiçoamento de Pessoal de Nível Superior - Brasil (CAPES) - Código de Financiamento 001.This study was financed in part by the Coordenação de Aperfeiçoamento de Pessoal de Nível Superior - Brasil (CAPES) - Finance Code 001. Atualmente é professor na FIESC/UNIESP, de Colinas/Tocantins. E-mail: edpsico@yahoo.com.br.

STROHSCHOEN, Andreia Aparecida Guimarães. Professora do PPGEnsino do curso de Mestrado em Ensino da Universidade do Vale do Taquari - UNIVATES. E-mail: aaguim@universo.univates.br.

OLIVEIRA, Eniz Conceição. Professora do PPGEnsino do curso de Mestrado em Ensino da Universidade do Vale do Taquari - UNIVATES. E-mail: eniz@ universo.univates.br.

DEL PINO, José Claudio. Professor do PPGEnsino do curso de Mestrado em Ensino da Universidade do Vale do Taquari - UNIVATES. E-mail: delpinojc@yahoo.com.br

Endereço para correspondência: Edgar Henrique Hein Trapp. FIESC/UNIESP, de Colinas/Tocantins. E-mail: edpsico@yahoo.com.br.

Como citar este artigo (Formato ABNT): TRAPP, Edgar Henrique Hein et al. Alfabetização científica e tecnológica - ACT na formação acadêmica superior. Educação, Psicologia e Interfaces, v. 3, n. 2, p. 136-147, 2019.

Recebido: 04/02/2018.

Aceito: 26/05/2018.

Educação, Psicologia e Interfaces, Volume 3, Número 2, 136-147, Maio/Agosto, 2019.

ISSN: 2594-5343. DOI: 